\title{
Improvements to a Flow Sensor for Liquid Bismuth-fed Hall Thrusters
}

\author{
Kevin Bonds* \\ Middle Tennessee State University, Murfreesboro, TN \\ 37132
}

\author{
Kurt A. Polzin ${ }^{\dagger}$ \\ NASA-Marshall Space Flight Center, Huntsville, AL \\ 35812
}

Recently, there has been significant interest in using bismuth metal as a propellant in Hall Thrusters [1, 2]. Bismuth offers some considerable cost, weight, and space savings over the traditional propellant--xenon. Quantifying the performance of liquid metal-fed Hall thrusters requires a very precise measure of the low propellant flow rates $[1,2]$. The low flow rates $(\sim 10 \mathrm{mg} / \mathrm{sec})$ and the temperature at which free flowing liquid bismuth exists (above $300^{\circ} \mathrm{C}$ ) preclude the use of off-the-shelf flow sensing equipment [3]. Therefore a new type of sensor is required.

The "hotspot" bismuth flow sensor, described in Refs. [1-5] is designed to perform a flow rate measurement by measuring the velocity at which a thermal feature moves through a flow chamber. The mass flow rate can be determined from the "time of flight" of the thermal peak, $[4,5]$. Previous research and testing has been concerned mainly with the generation of the thermal peak and it's subsequent detection. In this paper, we present design improvements to the sensor concept; and the results of testing conducted to verify the functionality of these improvements.

A ceramic material is required for the sensor body (see Fig. 1), which must allow for active heating of the bismuth flow channel to keep the propellant in a liquid state. The material must be compatible with bismuth and must be bonded to conductive elements to allow for conduction of current into the liquid metal and measurement of the temperature in the flow. The new sensor requires fabrication techniques that will allow for a very small diameter flow chamber, which is required to produce useful measurements. Testing of various materials has revealed several that are potentially compatible with liquid bismuth. Of primary concern in the fabrication and testing of a robust, working prototype, is the compatibility of the selected materials with one another. Specifically, the thermal expansion rates of the materials relative to the ceramic body cannot expand so much as to cause cracks in the body or cause the bond between parts to delaminate. Those parts that will carry the current pulse must be electrically conductive while the sensor body must be an electrical insulator. Generally, the material choices—as well as the sensor design-must aid to preserve the integrity of the thermal feature to obtain accurate measurements. The present aim is to also incorporate, into the sensor body, an active heating arrangement based on ceramic heater technology similar to that used in semiconductor manufacturing.

\footnotetext{
*Undergraduate Student, Aerospace Technology. Student member AIAA.

${ }^{\dagger}$ Propulsion Research Engineer, Propulsion Research and Technology Applications Branch, Propulsion Systems Department. Senior Member AIAA.
} 


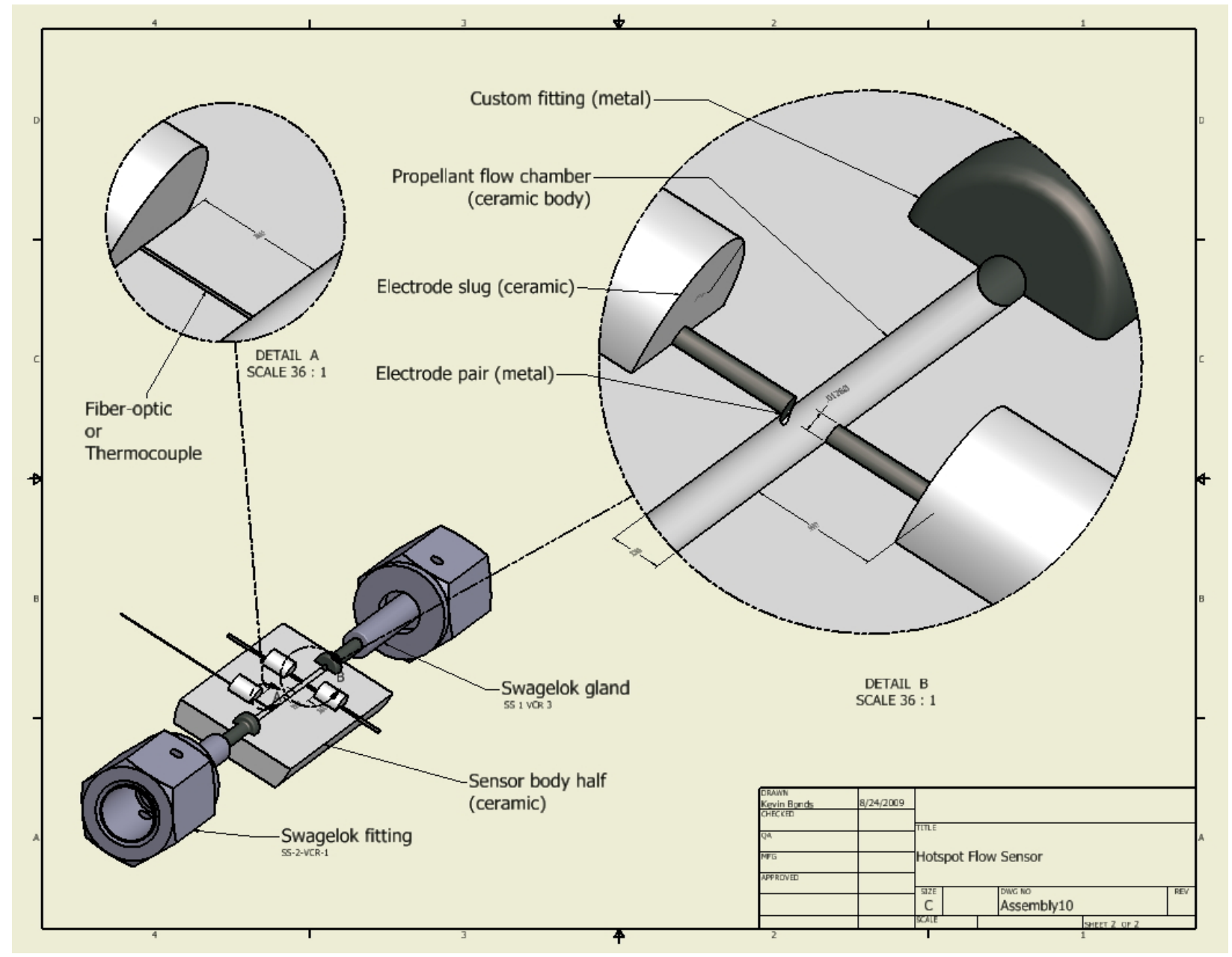

Figure 1. 3D CAD drawing of sensor body half, showing planned hardware placement

\section{References}

[1]. A. Sengupta, C. Marrese-Reading, M. Cappelli, D. Scharfe, S. Tverdokhlebov, S. Semenkin, O. Tverdokhlebov, I. Boyd, M. Keidar, A. Yanlin, V. Surla, T.E. Markusic, K.A. Polzin, "An overview of the VHITAL program: A twostage bismuth-fed very high specific impulse thruster with anode layer", in 29th International Electric Propulsion Conf., Princeton, NJ, Oct. 31 - Nov. 4, 2005. IEPC Paper 2005-238.

[2]. T.E. Markusic, K.A. Polzin, B.J. Stanojev, C. Dodson, and A. Dehoyos, "Liquid metal flow sensors for electric propulsion", Proc. 53rd JANNAF Propulsion Meeting, Monterey, CA, Dec. 2005.

[3]. K.A. Polzin, T.E. Markusic, B.J. Stanojev, C. Marrese-Reading, "Integrated Liquid Bismuth Propellant Feed System," 42nd AIAA Joint Propulsion Conference, Sacramento, CA, AIAA 2006-4636.

[4]. K.A. Polzin, V. Korman, T.E. Markusic and B.J. Stanojev. "System and Method for Determining Velocity of Electrically Conductive Fluid.” U.S. Patent 7,409,875, Aug. 2008.

[5]. C. Marrese-Reading, R. Swindlehurst, T.E. Markusic, K.A. Polzin, T. Knowles, and J. Mueller. "The Development of a Bismuth Feed System for the Very High Isp Thruster with Anode Layer (VHITAL) Program." Proc. of 42nd AIAA/ASME/SAE/ASEE Joint Propulsion Conference \& Exhibit, Sacramento, California, AIAA 2006-4635. 


\title{
Improvements to a Flow Sensor for Liquid Bismuth-fed Hall Thrusters
}

\author{
Kevin W. Bonds* and Kurt A. Polzin ${ }^{\dagger}$ \\ NASA-Marshall Space Flight Center, Huntsville, AL 35812
}

\begin{abstract}
A prototype bismuth flow sensor that measures mass flow rate by thermally tagging a fluid element and detecting the thermal feature downstream is presented. The design of this sensor seeks to address the manufacturing and operations issues that arose during the fabrication and implementation of previous versions of the sensor. A sensor body, fabricated from Macor, was successfully bonded to the various other components that comprise the sensor. Direct heating of the ceramic body is implemented to keep the bismuth from losing heat within the sensor. This is achieved by bonding a heater to the body in such a way that the heater is the fourth wall of the flow channel. Through several thermal cycles, these bonds have exhibited no signs of degradation or failure. An optical system was implemented to detect the light emission from the thermal feature, but the light emission from the metal at these temperatures is very low in the detector system's wavelength pass band. Options are proposed to either address the optical detection issues or to retrofit the sensor with a more conventional thermocouple measurement as was attempted in previous iterations of the sensor.
\end{abstract}

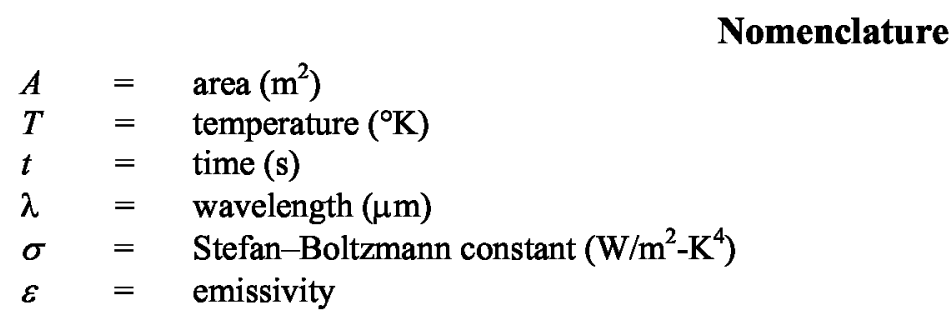

\section{Introduction}

$\mathrm{R}$ ecently, there has been significant interest in using bismuth metal as a propellant in Hall thrusters [1]. In addition to considerable cost, weight, and space savings, bismuth appears to offer significant performance advantages over Hall thrusters operating on xenon propellant [2]. Accurately quantifying the performance of a bismuth-fed Hall thruster requires a very precise, real-time measure of the low propellant flow rates $[1,3]$. The low flow rates $(\sim 10 \mathrm{mg} / \mathrm{sec})$ and the temperature at which bismuth melts and freely flows (above $300^{\circ} \mathrm{C}$ ) preclude the use of off-the-shelf flow sensing equipment [4]. The "hotspot" bismuth flow sensor, described in Refs. [1, 3-6], was designed to address this deficiency. The sensor is designed to perform a flow rate measurement by measuring the velocity of the fluid using a thermal tagging technique. A thermal feature, introduced into the flow using a current pulse to Ohmically heat the fluid, is convected downstream of the heating location until it reaches a thermal detector. Through calibration, the mass flow rate can be correlated to the "time of flight" of the thermal peak between the locations of creation and detection [5].

While the present work is primarily concerned with sensing the flow rate of liquid bismuth, liquid gallium was used for some testing described in this paper because it is easy to handle and is a liquid at near room temperature. Bismuth has a melting point of $271^{\circ} \mathrm{C}$ and expands $3.32 \%$ in volume during solidification, while gallium has a melting point of $29.6^{\circ} \mathrm{C}$ and expands $3.1 \%$ [7].

\footnotetext{
${ }^{*}$ Undergraduate Student, Middle Tennessee State University. Student Member AIAA.

${ }^{\dagger}$ Propulsion Research Engineer, Propulsion Research and Technology Applications Branch, Propulsion Systems Department. Senior Member AIAA.
} 
Issues that arose in the fabrication and testing of previous versions of the sensor have guided our efforts to improve upon the robustness and reliability of the sensor. The purpose of the present work is to demonstrate that a robust, reliable flow sensor can be fabricated and used to measure bismuth flow rates. Several flow sensor body candidate ceramic materials were tested for their compatibility with hot liquid bismuth. In addition, new bonding agents were used to join the ceramic material, comprising the body of the sensor, with other materials required for operation. Finally, a fiber-optic temperature detection system, previously discussed in Ref. [5], was implemented to detect the thermal feature downstream of the heating location. Each of these subtopics is discussed within the body of this paper. While a fully-operational sensor has yet to be demonstrated, design and testing aimed at quantifying the performance of the new prototype sensor is described.

\title{
II. Hotspot Sensor Description
}

The principle of operation of the flow sensor is illustrated in Fig. 1a. A pulse of thermal energy (derived from a current pulse and associated joule heating) is applied near the inlet of the sensor. The flow is tagged with a thermal feature that is convected downstream by the flowing liquid metal. A downstream thermocouple or other temperature measurement device records a ripple in the local temperature associated with the passing hot spot in the propellant stream. By measuring the time between the upstream generation and downstream detection of the thermal feature, the flow speed can be calculated using a time-of-flight analysis. This sequence of events is illustrated in Fig. $1 \mathrm{~b}$. The spatial temperature distributions at two different times, $t_{0}$ and $t_{1}$, are conceptually illustrated. At time $t_{0}$, current is pulsed through the liquid and the temperature at the heating location locally spikes; the temperature at the thermocouple location remains at the constant, equilibrium value. At some later time $t_{1}$, the thermal feature that was created at time $t_{0}$ reaches the thermocouple location and a spike in the temperature profile is observed. This spike will be somewhat smaller in peak temperature and broader in spatial extent because the thermal feature will diffuse as it is convected downstream.

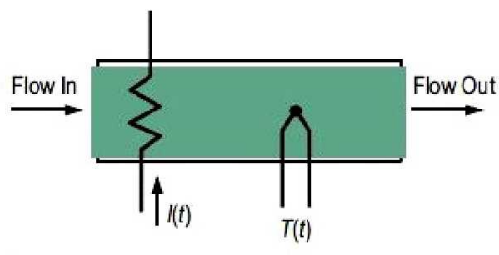

(a)

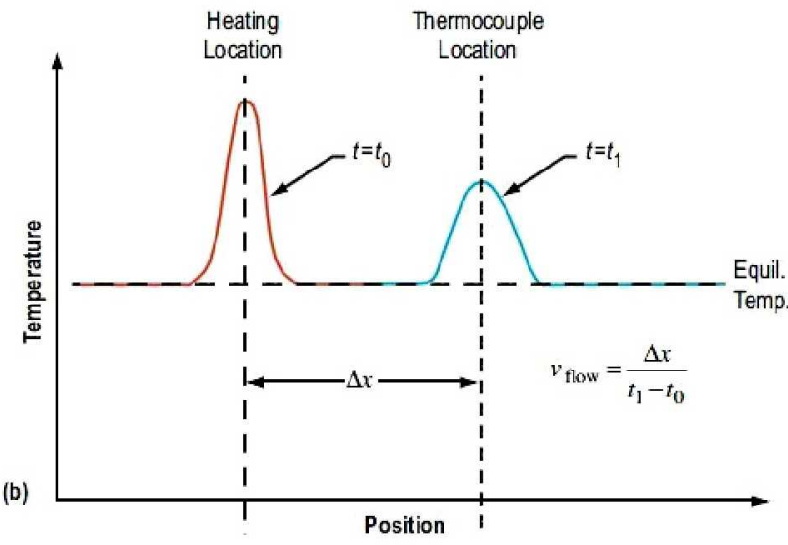

\begin{abstract}
Figure 1. (a) Schematic illustrating the principle of operation using a thermocouple for peak determination and (b) Conceptual evolution of the hotspot displacement inside the sensor.
\end{abstract}

The primary advantage of this technique is that is does not depend on an absolute measurement of temperature but, instead, relies on the observation of thermal features. This makes the technique insensitive to other externally generated, low-frequency thermal fluctuations. The hot spot in the upstream flow is generated by pulsing current directly through the liquid metal; doing so exploits the intrinsic resistivity of the fluid and obviates the need for a separate resistive heating element. In order for the hotspot sensor to provide useful results, the spatial integrity of the hot spot must be maintained until it reaches the location of the thermal detector. The hot spot will tend to flatten as it propagates, due to thermal diffusion. Therefore, the device must be designed such that the thermal diffusion timescale is much longer than the convective timescale.

\section{Materials Testing and Considerations}

The sensor body is fabricated from a ceramic material, which must allow for active heating of the bismuth flow channel to keep the propellant in a liquid state. The material must be compatible with bismuth and must be bonded 
to various elements to allow for connection to the rest of a flow system, conduction of current into the liquid metal, and measurement of the temperature in the flow. The sensor must possess a small diameter flow channel to produce useful measurements.

Testing of various materials has revealed several that are potentially compatible with liquid bismuth. This was investigated by placing bismuth pellets (roughly $0.5-0.75 \mathrm{~g}$ ) on small (roughly 2 -cm square) samples of different ceramics. The furnace temperature was then elevated to a peak of roughly $660^{\circ} \mathrm{C}$ - well above the melting temperature of bismuth. The total time above $350^{\circ} \mathrm{C}$ was approximately $15 \mathrm{hrs}$. Samples tested included $96 \%$ and 99.5\% purity alumina $\left(\mathrm{Al}_{2} \mathrm{O}_{3}\right)$, aluminum nitride (AIN), silicon nitride $\left(\mathrm{Si}_{3} \mathrm{~N}_{4}\right)$, and boron nitride (BN). In addition to these materials, the compatibility of bismuth with Macor (glass-mica ceramic) has already been learned through previous testing [3,4]. It was found that the liquid bismuth did not 'soak into' the parent ceramic material in all cases. After the bismuth cooled and solidified, it could easily be removed from the ceramic surface. Two sample images of the surface obtained using a scanning electron microscope (SEM) are displayed in Figs. 2 and 3. The small, bright points in each figure arise from tiny pieces of bismuth remaining on the surface after the bulk material was removed. In Fig. 2, there are also several light-gray areas, and evaluation of these areas was conducted using an energy dispersive spectrometer (EDS). The data obtained through both the SEM imagery and the EDS analysis revealed that there was no significant degradation of the ceramic material and bismuth did not significantly penetrate the surface of the materials mentioned above.

A concern in the fabrication and testing of a robust, working prototype is the compatibility of the selected materials with one another. Specifically, the goal is to match the thermal expansion rates of the materials bonded to the ceramic body to mitigate or eliminate the risk of material cracking or delamination during thermal cycling of the sensor.

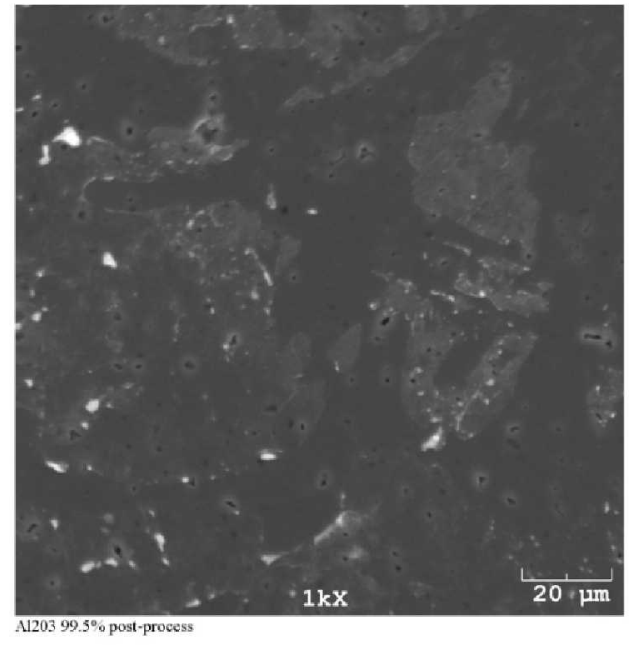

Figure 2. SEM image of $99.5 \%$ purity $\mathrm{Al}_{2} \mathrm{O}_{3}$, after exposure to molten bismuth.

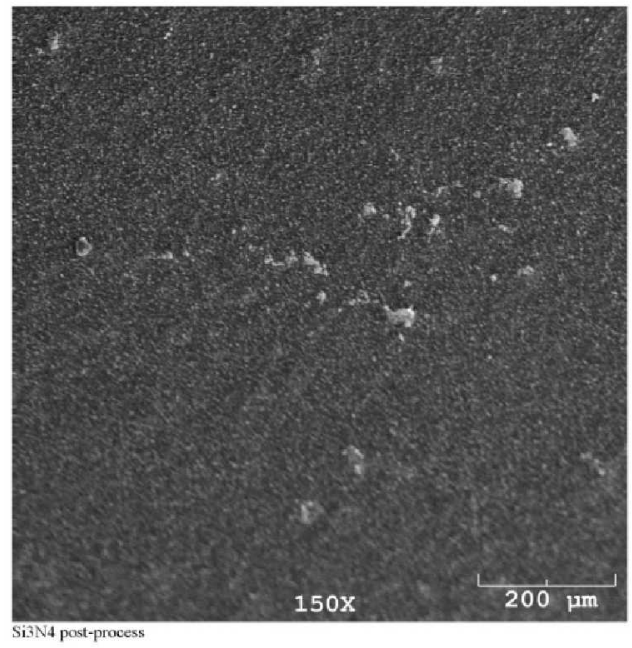

Figure 3. $\mathrm{SEM}$ image of $\mathrm{Si}_{3} \mathrm{~N}_{4}$, after exposure to molten bismuth.

\section{Flow Sensor Design and Fabrication}

\section{A. Design Considerations}

The low volumetric flow rate $(0.1-1.0 \mu \mathrm{L} / \mathrm{sec})$ of the propellant requires a small flow chamber cross-sectional area to maintain a high-enough flow speed to allow for useful "time of flight" measurements $[5,8]$. Such a small flow chamber presents difficulties during machining and assembly of the sensor. Machinable ceramics tend to be brittle, thermally insulating, and possess a low coefficient of thermal expansion. The brittle nature of the ceramics requires control of the spindle speeds and feed rates during the machining phase and the implementation of significant strain relief, especially of the external hardware bonded to the ceramic body, during the assembly and testing phases. The low coefficient of thermal expansion makes it difficult to mate the ceramic body with materials that have higher coefficients of thermal expansion, such as the metals that comprise the flow sensor fittings, piping, and electrodes. 
The selection of bonding materials and potting compounds presents another problem in that the material must survive the high temperature required to liquefy bismuth, but it also must survive the thermal expansion and contraction cycles of the ceramic flow sensor and the other components being bonded to it. In addition, these materials can come into contact with the molten bismuth and, like the ceramic body they must not interact with the flowing metal.

\section{B. Sensor Hardware}

A rendering of the sensor is shown in Fig. 4 and the assembled sensor is shown photographically in Fig. 5. The sensor body is fabricated from Macor, and programmable CNC machining is employed to give precision control over the dimensions. While Macor was used for this flow sensor due to its machinability, future iterations could be fabricated out of one of the many ceramic candidates tested above depending on the ruggedness desired and the restrictions on the different coefficients of thermal expansion between individual parts of the sensor. The flow channel was machined to a depth of 0.020 " using a 0.031 " diamond-coated endmill, resulting in a target crosssectional area of the flow chamber was $0.744 \mathrm{in}^{2}$. A small, flat ceramic heater manufactured by Kyocera Corporation is bonded to the flow sensor and used for active heating of the flow channel. To ensure the propellant remains in the liquid phase, the ceramic heater is placed in direct contact with the flow. The design of the sensor is such that one side of the flow chamber is left open during machining, allowing the heater to be bonded to the sensor body to form the fourth side of the flow channel. A layer of epoxy (ceramic-based adhesive made by Aremco) of uniform thickness and precise depth is applied to the Macor and then the heater is placed on the surface, bonding them together. It is imperative that that epoxy is not squeezed into the flow chamber during the bonding process. While a bit of thinning of the epoxy is expected during the process of pressing the two surfaces together, the epoxylayer was applied with a thickness of $4.5 \mathrm{mils}$.

The electrodes used to introduce the 'hotspot' into the fluid and the fiber optic used to optically detect the thermal feature downstream of the electrodes are both bonded to the sensor body perpendicular to the flow channel. The electrodes enter in a plane parallel to the heater wall while the fiber is perpendicular to the heater surface. The electrode channel was machined using a 0.020 " diamond-coated, ball endmill while the hole for the bare fiber was drilled with a \#74 drill. The streamwise distance from the electrode channel to the fiber hole is $1 \mathrm{~cm}$. The electrodes are 0.016 inch diameter tungsten wire and the fiber is $400 \mu \mathrm{m}$ multimode silica fiber. As with the heater, these components were bonded to the ceramic using an alumina ceramic-based epoxy.

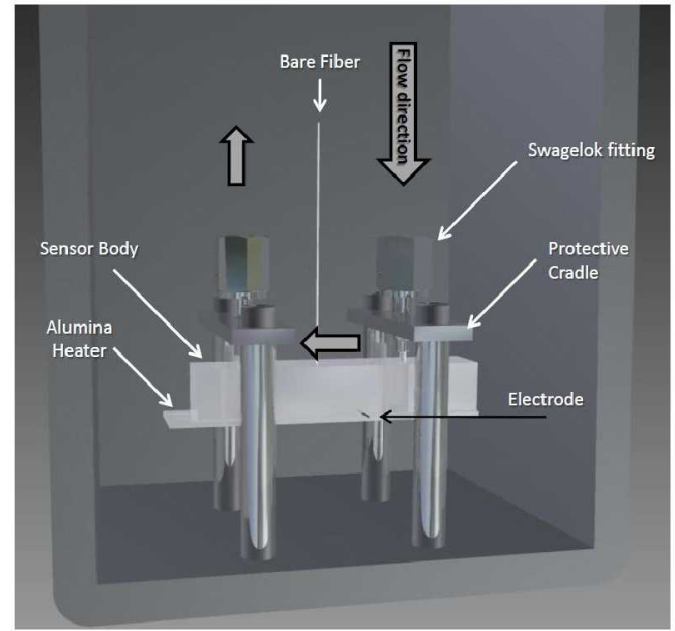

Figure 4. Rendering of the flow sensor design.

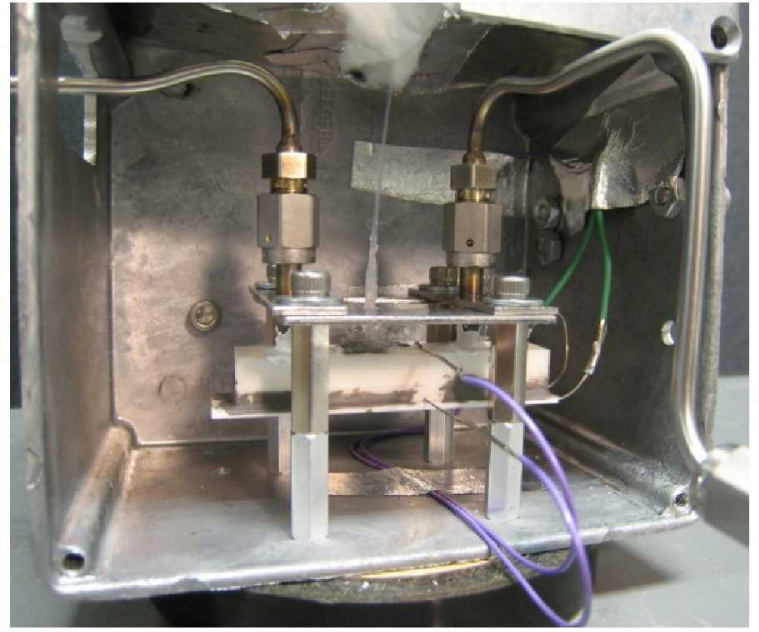

Figure 5. Photograph of the assembled sensor.

As a method of strain relief the ceramic body is suspended in a bolted cradle assembly. The cradle assembly is attached to the ceramic body only by the propellant inlet and outlet tubing which is attached to the fitting through welding. The small $(0.062 \mathrm{in}$.) stainless steel tubing is bonded to the ceramic using the alumina ceramic-based epoxy. The contact area of the flow sensor exposed to the much more thermally-conductive stainless steel tubing is minimized by using such a small diameter tubing, restricting the heat losses from the system. The fittings, Swagelok VCR glands and female VCR nuts, are tack-welded to the cradle assembly to permit easy installation and removal of the feed lines without placing strain on the ceramic body. 
The fiber to ceramic junction also required a method of strain relief. J-B Cold Weld epoxy was used at the base of the junction to provide tensile strength and RTV silicon was used to build a flexible boot outside of the epoxy. Both products are malleable enough during application to be applied without fear of damage to the fiber in the process. The epoxy has, to date, withstood exposure to both hot bismuth and gallium, and it has proved to be useful in fixing small leaks at the various material interfaces.

\section{Optical System}

During flow sensor operation the fiber is in direct contact with the fluid. This simplifies the calculations for spectral radiance since the angular and directional distribution can be neglected and emissivity can be calculated as the total hemispheric radiance for a $400 \mu \mathrm{m}$ diameter spot for the given material at a given wavelength and temperature. However the shape of the emissivity curves for both bismuth and gallium at the flow sensor operating temperatures are not well known. In the absence of data on the topic assumptions must be made based on the emissivity of a black body. The spectral radiance for a black body is the familiar [9]:

$$
P=\sigma \varepsilon A T^{4}
$$

Using Wien's law the wavelength of maximum light emission intensity for a given black body temperature is

$$
\lambda_{\max }=2898 / T
$$

Wein's law indicates that the wavelength corresponding to the maximum intensity of emitted radiation is inversely proportional to the absolute temperature of the emitting surface. Consequently, as temperature increases the wavelength decreases [10]. The peak wavelength for various blackbody temperatures is given in tabular form in Table 1.

Table 1. Wavelength of peak intensity for a given black body temperature.

\begin{tabular}{cc}
\hline \hline$\left({ }^{\circ} \mathbf{C}\right)$ & $(\boldsymbol{\mu m})$ \\
150 & 6.85 \\
200 & 6.12 \\
250 & 5.54 \\
300 & 5.06 \\
350 & 4.65 \\
400 & 4.30 \\
\hline
\end{tabular}

Generally, emissivity is low for a highly reflective surface [11-13]. The materials in question are highly reflective and little is known about the shape of their spectral radiance curves at various temperatures. Neither material has been extensively studied as neither enjoys wide usage in industrial applications. Without emissivity curve data it is difficult to estimate the amount of total photon energy that is being transmitted to the fiber. Further complicating matters are the losses associated with fiber transmission and the inherent spectral response curve of the photodetector.

Two different InGaAs photodiode based systems were tested to evaluate the feasibility of using an optical system for peak temperature determination. One photodetector has a response to wavelengths in the 1.2-2.6 $\mu \mathrm{m}$ range while the other operates in the $0.7-1.8 \mu \mathrm{m}$ range. The $400 \mu \mathrm{m}$ single-strand bare silica fiber has a spectral response in the 0.4-2.2 $\mu \mathrm{m}$ range. Detection was attempted with both InGaAs detectors over a temperature range of $150-350^{\circ} \mathrm{C}$ for both bismuth and gallium. A type $\mathrm{K}$ stainless steel sheathed thermocouple was used for temperature comparison. However, Table 1 indicates that the wavelength range for both detectors and silica fiber are all quite far from the wavelength of peak emission for a blackbody at the temperatures tested. Consequently, the signal from the photodiodes was dominated by noise and not very useful 


\section{Current Status and Future Testing}

The primary difficulty that has arisen in the present prototype flow sensor concerns the ability to sample the hotspot temperature accurately using the optical technique. Stated simply, the intensity of the light emitted from bismuth and gallium is too low in the pass-band of our optical detection system to permit discernment of the hot spot. This is complicated by the emissivity of both materials being low at these temperatures; and the emissivity of bismuth shifting as it oxidizes. One possible option is to redesign the detection hardware so that the wavelength pass band permits the passage of longer wavelength light. Another possible option is to dope the end of the current fiber in a material that will emit more light in the system's pass band, serving as an intermediary between the bismuth or gallium and the detection system.

Another option is to construct a new sensor that directly measures temperature using a thermocouple. Problems were encountered with the thermocouple measurement in previous iterations of the flow sensor primarily because the probe had to be inserted into the flow channel through what was, essentially, a blind hole. This made it extraordinarily difficult to align the thermocouple within the flow channel. In the present iteration, however, the flow channel is initially exposed, which may make it significantly easier to install a thermocouple into the setup. One additional issue encountered when using thermocouples was the relatively slow response time associated with thermocouple data acquisition systems. This served to limit the resolution on the flow rate measurement, but since an absolute temperature measurement is unimportant for the sensor, it may be possible to amplify the thermocouple signal and then use standard (and faster) data acquisition systems.

Once a reliable method to measure the temperature has been validated, the flow sensor will be calibrated to correlate the time of flight of the hot spot pulse to the flow rate. This will be performed by expressing the liquid metal onto a scale to directly measure the mass flow rate as a function of time while simultaneously pulsing the system many times during the calibration to obtain time of flight data.

\section{Conclusion}

We have presented a new prototype hotspot bismuth flow sensor that seeks to address issues that had been associated with the manufacturability and operability of previous iterations of the device. Many ceramics were tested for their compatibility with hot, liquid bismuth and showed resistance to the molten liquid. The sensor body was fabricated from the machinable ceramic Macor, which was successfully mated to the other parts of the sensor without leaks. All materials have remained bonded during several thermal cycles with no sign of degradation or loss in joint integrity. Direct heating has been implemented to minimize the heat loss of the fluid while it passes through the sensor. An optical temperature detection system was implemented in the present design to monitor the hot spot as it was convected downstream, but at present this has proven inadequate owing to the low emission of light in the detector system's wavelength pass band. Options to address this issue include attempting to shift the emission into the pass band of the optical detection system or retrofitting the sensor with a thermocouple measurement in a manner similar to that attempted in previous iterations.

\section{Acknowledgments}

We acknowledge the assistance in materials testing provided by Dr. Ahmad Vakili, Mr. Joel Davenport, and Ms. Katherine Lansford of the University of Tennessee Space Institute. We would also like to thank Dr. Andrew Wereszczak at Oak Ridge National Laboratory, Ms. Sheila Murphy at Kyocera Corporation, and Dr. Valentin Korman of K Sciences for providing material samples and offering advice during the course of this project. Invaluable machining and fabrication assistance was provided by Mr. Rick Taylor at Middle Tennessee State University and Mr. Keith Chavers at NASA-MSFC. We acknowledge the help of Mr. Adam Kimberlin and Mr. Ryan Sullenberger, and want to thank Mr. J. Boise Pearson of NASA-MSFC for his continued support during this project.

Project funding and assistance were provided by Dr. Tom Cheatham, Ms. Rose Johnson, Dr. Mark Abolins, Dr. Ahad Nasab, Dr. William Robertson, and Ms. Sally Swoape of Middle Tennessee State University.

\section{References}

[1] A. Sengupta, C. Marrese-Reading, M. Cappelli, D. Scharfe, S. Tverdokhlebov, S. Semenkin, O. Tverdokhlebov, I. Boyd, M. Keidar, A. Yalin, V. Surla, T.E. Markusic, and K.A. Polzin, "An overview of the VHITAL program: A twostage bismuth-fed very high specific impulse thruster with anode layer," in 29th International Electric Propulsion Conf., Princeton, NJ, 2005. IEPC Paper 2005-238. 
[2] S.O. Tverdokhlebov, A.V. Semenkin, and J.E. Polk, "Bismuth propellant option for very high power TAL thruster," in 40 th AIAA Aerospace Sciences Meeting, Reno, NV, 2002. AIAA Paper 2002-348.

[3] T.E. Markusic, K.A. Polzin, B.J. Stanojev, C. Dodson, and A. Dehoyos, "Liquid metal flow sensors for electric propulsion," Proc. 53rd JANNAF Propulsion Meeting, Monterey, CA, 2005.

[4] K.A. Polzin, T.E. Markusic, B.J. Stanojev, and C. Marrese-Reading, "Integrated Liquid Bismuth Propellant Feed System," in $42^{\text {nd }}$ AIAA/ASME/SAE/ASEE Joint Propulsion Conference, Sacramento, CA, 2006. AIAA paper 2006-4636.

[5] K.A. Polzin, V. Korman, T.E. Markusic, and B.J. Stanojev, "System and Method for Determining Velocity of Electrically Conductive Fluid," U.S. Patent 7,409,875, Aug. 2008.

[6] C. Marrese-Reading, R. Swindlehurst, T.E. Markusic, K.A. Polzin, T. Knowles, and J. Mueller, "The Development of a Bismuth Feed System for the Very High Isp Thruster with Anode Layer (VHITAL) Program," in $42^{\text {nd }}$ AIAA/ASME/SAE/ASEE Joint Propulsion Conference, Sacramento, California, 2006. AIAA paper 2006-4635.

[7] P. Patnaik, Handbook of Inorganic Chemicals, McGraw-Hill, New York, 2003.

[8] K.A. Polzin, T.E. Markusic, and B.J. Stanojev, Liquid Bismuth Propellant Management System for the Very High Specific Impulse Thruster With Anode Layer, Tech. Rep. NASA/TM-2007-214958, Marshall Space Flight Center, AL, 2007.

[9] D. Halliday, R. Resnick, and J. Walker, Fundamentals of Physics, 8th ed., Wiley, New York, 2008. Chapter 18.

[10] 2009 ASHRAE Handbook - Fundamentals (SI Edition), American Society of Heating, Refrigerating and Air Conditioning Engineers, Inc., 2009.

[11] G. Gaussorgues, Infrared Thermography, Chapman \& Hall, London, 1994. Chapters 3, 9.

[12] G.P. Dewitt and G.D. Nutter, Theory and Practice of Radiation Thermometry, Wiley, New York, 1988. Chapters $1,2$.

[13] M. Schlessinger, Infrared Technology Fundamentals, Marcel Dekker, New York, 1995. Chapters 3, 9. 